\title{
Wiki, a New Wave of Innovation for Teaching and Collaborative Learning
}

\author{
Hassan Mirzajani (Corresponding author) \\ Faculty of Educational Studies, Universiti Putra Malaysia, 43400 UPM, Serdang, Selengor, Malaysia \\ E-mail: mirzajanihassan@yahoo.com \\ Kobra HajiAlizadeh \\ Department of Psychology, Bandar Abbas Branch, Islamic Azad University, Iran \\ Omolbanin Hashemi Gorji \\ Department of Educational Psychology, Islamic Azad University, Shahrekord Branch, Iran \\ Romina Zerafat \\ Department of Management Lincoln University College Malaysia, Branch Iran \\ Hanieh Rasouli Saravi \\ Department of Management Lincoln University College Malaysia, Branch Iran \\ Reza Alami \\ Department of Management Lincoln University College Malaysia, Branch Iran
}

Received: 14-08- 2015

doi:10.7575/aiac.ijels.v.3n.4p.1
Accepted: 11-09-2015

URL: http://dx.doi.org/10.7575/aiac.ijels.v.3n.4p.1

Published: $31-10-2015$

\begin{abstract}
Educational technology is a dynamic major which is ever developing. In the past, educational technology was one dimensional, but nowadays it has become multi-dimensional, flexible and learner-centered. A revolution has happened in teaching methods from the perspective of web. Novel technologies in web and new role of users' have led to the appearance of application programs on the basis of collaborative and social intelligence. Users have active participation, exploit their own beliefs, make the target concept, edit it and participate there. The most important feature of this kind of media is users' ability to participate in its content production. Users can exploit wikis in the process of educational technology. A wiki is a social medium which enables users to produce and edit constantly in an HTML environment. The aim of this article is to introduce wikis as educational and training tools. The degree to which these obstacles affect ICT users and institutes can support decision-making on how to equip them is discussed.
\end{abstract}

Keywords: educational technology, wiki, collaborative learning, innovation

\section{Introduction}

Educational technology encompasses a broad range which is developing with the appearance of new theories and technologies. During the recent years, new approaches in learning have been changed by the appearance of novel technologies such as media, hyper media, and telecommunications (Terry, Anderson, Grayson, 2003). Rapid changes in information and communication technology during the recent years have led to innovation in communication and information sharing. Innovation in Higher Education helps the process of learning and teaching (Mirzajani et al., 2015). In the past, educational technology was one dimensional, hardware based, machine simplistic with pre-determined structure; however, nowadays it has become multi-dimensional, flexible, humanistic, learner-centered without any predetermined structure. These days, students do not simply receive content but rather they create it. Learners are not limited to specific time and place; they have information access whenever they wish.

In order to learn, people should gain information from a source. Day by day different tools, methods and technologies are presented in learning and teaching. These technologies can make learners more independent. E-learning and webbased technologies are one of the methods in this field. Social media can make the relationship between people with the same interests. Since learning is a social process, social media and software are beneficial in this process. Exploiting these media, learners that are actively responsible for their learning create knowledge in the process. While content is produced in a collaborative educational environment, learning also takes place (Kerbs, Ludwing, \& Muller, 2010). In 
order to have a better student-teacher and student-student interaction new tools are needed. Social media support group work to reach a shared goal. Social software consists of application programs such as wikis, weblogs and social networks for sharing multimedia, audio, video and text content. Social networks support learning in different ways such as sharing resources, collaborative learning and peer-peer education. They can also facilitate the relationship between participants by providing knowledge. Software offers new situation for collaboration and new facilities for learning and education (Grant, 2006).

A wiki, as a social network, has a key role in making collaborative content. The most common usage of wikis is in projects with training course content (Fountain, 2005). In these situations, the content of wikis can be managed and edited in a collaborative way. A wiki is used as a tool for educational goals. They present special facilities to learners. A learner in a wiki is not just a learner but a creator and an editor of content. The learner debates with others present in the wiki. Wikis are websites that enable users to develop, distribute and share content with no need to programming skills (Chang, Morales, \& Than, 2010). This paper focuses on the use of wiki technology in the classroom, beginning with a brief look at learning attitudes that can be promoted from wikis. It also reviews the current state of wiki use in education, looks at the additional uses of wiki technology in teaching and learning process, and finally concludes with a discussion of appropriate uses of wikis.

\section{What is a wiki?}

Franklin and Van Harmelen (2007) define a wiki as "a system that allows one or more people to build up a corpus of knowledge in a set of interlinked web pages, using a process of creating and editing pages" (p.5). A wiki is a popular technology in communication. The term originates from 'Wee Kee Wee Kee' (meaning: quick and rapid). The term in information technology shows an HTML tool which is web based and enables developing of content from different people (Biasutti \& EL-Deghaidy, 2012). According to Ramanau and Geng (2008), a wiki is a collection of connected web pages that enables users to create and edit their own content. A wiki is, therefore, an environment that users produce content collaboratively. A wiki is a simple sample of web tools that does not need any specific software. It works like a word processor which is used to develop collaborative environment (West \& West, 2008). Structurally, wikis are different from web based media (weblogs and e-mails). In fact a wiki provides a useful method for keeping information by group work and inserting it on web pages. Using these technologies enables users to contribute their own content as well as edit or delete the current content (Alexander, 2006). A wiki can record the edited content. In fact, a wiki has the ability to retrieve the content of the older versions. Thus, a wiki is a proper tool in collaborative activities in which individuals intend to create content (Kane \& Fichman, 2009).

Wikis are online and dynamic web sites that are made by collaboration of multi-users in a web browser (Wagner $\&$ Majchrzak, 2007). Wikis are different from other websites because they enable the users to participate, edit and update the content (Hester \& Scott, 2008). Everybody can make a new page in a wiki or edit and delete other pages to develop a collection of connected web pages (Leuf \& Cunningham, 2001). The first wiki (still accessible at http:// c2.com/cgi/wiki) was made by Cunningham, a software company in Oregon State in 1995 (Standing \& Kiniti, 2011). According to Choate (2008), the goal of Cunningham was to use a global network. Wikipedia is the most popular online encyclopedia which is conducted by Wikimedia, a web-based software program. The term Wikimedia is made by merging wiki and encyclopedia. Wikipedia was created in 2001, and more than 3 million articles were uploaded there until 2009. Users can visit, read, reorganize and update the structure and content (text and pictures) of Wikipedia.

\section{The Review of Literature}

Franco (2008) used a wiki in a study with the aim of teaching English. He asked his students to correct their group members in the wiki. The results showed that the students were positive in using the wiki which was developed in English. According to Gokcearslan and Ozcan (2011), a wiki can help collaborative learning by using computers. He believes that the task in a group work has to make students work together which can help them enhance the process of memorization and thought. Ramanau and Geng (2008) conducted a study on the application of wikis in facilitating group work among university students. The results showed that according to learners this technology is beneficial in learning.

Mahdavi Nsab (2001) investigated the influence of weblogs on university students' collaborative learning. The study was conducted on 37 undergraduate Allameh-Tabatabai University students of Learning Management in Semester 2. The results indicated that using weblogs as collaborative learning tools positively influenced collaborative learning elements as well as students' views towards using weblogs for collaborative learning. Hampel, Selke, and Vitt (2005) presented different models in using wikis at schools such as collecting information and links for a specific goal, recording issues in brainstorming sessions and web surfing. Duffy and Bruns (2006) presented a plan for different applications of wikis. According to them wikis could be used for the documentation of students' activity, using their mind and making collaborative and complete content as a network connected to resources. Notari (2006) used wikis in learning biology. He emphasized the importance of communication, culture of commenting, and also enabling learners to make specific portion of input in a short period of time. Lamb and Johnson (2007) argue that wikis are proper tools for electronic folders, portals, study guides, dynamic magazines and notebooks, as well as being helpful for virtual seminars and resources' editors. They come to conclusion that as a result of wiki students developed in writing. According to Lin and Kelsey (2010), since wiki documents are dated, learners can collaboratively update them without having to worry about losing documents or the correspondence date. Students can do their jobs wherever they are even 
when they are absent. Avci and Askar (2011) investigated wikis as tools for learning-teaching and compared them with real teaching sessions in reference to usefulness, ease of access, hardness, independence and stress. The analysis of the data collected from 92 participants indicated that using wikis and weblogs plays a positive role in learning.

\section{Technological Properties of Wikis}

\subsection{Collaborative Learning}

Wikis are not conducted by one person; rather, different people contribute to their content. Thus, a wiki is an influential tool for group work which gives the chance for sharing knowledge and experiences for learners (Beyer, 2012). This kind of learning is situated within the social collaborative paradigm. Students work on projects or problems both in teams and individually. Lin and Hsieh (2001) stated, "earning occurs as individuals exercise, verify, solidify, and improve their mental models through discussion and information sharing" (p. 379). A wiki is a tool that shapes its audience and enables democratic collaboration among members (Barton, 2004). Parker and Chao (2007) declare that collaborative learning has been "approached from a variety of perspectives in wiki research, including reflective activity and communal or social constructivism" (p. 59).

\subsection{Immediate Publish}

New pages are published immediately in a wiki since there is no editor for reviewing. As the published content is visible immediately, there will be a chance for other users to have more time in editing.

\subsection{Versioning}

Early Editions are saved in temporary information banks of the wiki which works as a security guard against accidental damage and vandalism and also provides a path for positioning previous changes such as the writer, date and other related information (Shirky, 2003).

\subsection{Simple Writing}

Writing style in wikis is simple and the user does not need to be tech-savvy to publish documents. Users can start by writing a simple article. The links will be developed by a double click.

\subsection{Simple Language Format}

Wiki's language format is simpler than HTML and a new page can be developed without internal links or side programs (Lamb, 2004). Although some of wikis pages are in HTML format, the quality of the wiki is laid on them (Turnbull, 2004).

\subsection{Simple Language}

In order to make and change wiki's content, there is no need to use programming languages by users. Using a wiki is as easy as the use of the MS Word.

\subsection{Traceability}

Using a wiki enables one to see the changes on web pages.

\subsection{The Public Oversight}

Since the environment process of wiki consists of a group of people, people can see the processes. That is why there is a high speed and function (Gokcearslan \& Ozcan, 2011).

\section{Technology in Wikis}

The characteristics of wikis such as production of knowledge, participation of people, structuralism and collaborative learning are intertwined, since in structuralism active participation is emphasized and learning is the production of collaboration (Cole, 2009). According to collaborative learning, learners are put in small groups and help each other to reach educational goals (Johnson \& Johnson, 1991). This method is used to help students have active participation in the process of learning, and in this way they can be more successful (Carlan, Rubin, \& Morgan, 2005). On the other hand, information is exchanged better in this method (Grant, 2009).

\section{Discussion and Conclusion}

In our technological world, there are numerous new technologies that can be used by students via online learning platforms and the internet in schools. The need for instructors to access these innovations in schools is becoming increasingly important as the young generation is already exposed to them in their daily social situations. During the past decades, web-based collaborative learning tools based have rapidly developed. In this field, the competition is serious and organizations require knowledge to survive (Mirzajani et al., 2015). The technology is based on web that enables users to have collaboration in creating the content. Users can make new content and even edit or delete it. They can do these activities quickly with no need for technical knowledge and complete them with the help of other users.

The most important strength of a wiki is users' ability to use it. Sometimes users cannot use web 2 due to the lack of knowledge. According to Oblinger and Oblinger (2005), educational centers should not view students as experts in a network. In fact, it should not be assumed that living in the age of information and communication technology cannot enable them to do so. Pifarré and Li (2012) in an analysis of teacher-student interaction in wiki-based environment found that wikis do not necessarily provide a good environment for student learning but collaborative learning is 
significantly improved by them. Therefore, learning should be planned in a way that it can influence teacher-student interaction. Pifarré and $\mathrm{Li}$ (2012) also found that the practical part of wikis was not considered by teachers and recommended teachers to improve their learners' writing and editing skills before leading them to wikis.

As the literature indicated, wikis have the potential to be used to promote collaboration, provide instruction, and disseminate information among students. Integrating wikis may result in problems; therefore, the following recommendations should be considered before using them as learning tools. First, the teacher should consider the objectives of using the wiki technology. Moreover, when syllabus designers are considering integrating wikis-based learning into a course, they should ensure that the course objectives are aligned with the students' abilities. In addition, some teachers may feel afraid by using new technologies into their existing courses or be worried about their ability to control the accuracy of the information on wiki pages. Finally, Macdonald, Weller, and Mason (2002) pointed out that "Networking opens up possibilities for enhancing formative feedback to students through peer review, when scripts are posted electronically for comment and review" (p. 10). Therefore, if teachers wish to use wiki technology for tasks like student assignments, they should know that they can give helpful feedback through the wiki used for the assignment.

\section{References}

Alexander, B. (2006). Web 2.0: A new wave of innovation for teaching and learning? Educause Review, 41(2), 32.

Avci, U., \& Askar, P. (2011). The Comparison of the opinions of the university students on the usage of blog and wiki for their courses, Educational Technology \& Society, 15, 194-205

$\begin{array}{llllll}\text { Barton, } & \text { M. } & \text { (2004). } & \text { Embrace the wiki } & \text { way. } & \text { Retrieved from }\end{array}$ pttp://www.mattbarton.net/tikiwiki/tikiprint_article.php?articleId= on

Beyer, D. A. (2012). Enhancing critical reflection on simulation through Wikis. Clinical Simulation in Nursing, 8(2), e67-e70.

Biasutti, M., \& EL-Deghaidy, H. (2012). Using Wiki in teacher education: Impact on knowledge management processes and student satisfaction. Computers \& Education, 59(3), 861-872.

Carlan, V., Rubin, R., \& Morgan, B. (2005, June 10). Cooperative learning, mathematical problem solving, and Latinos. International Journal for Mathematics Teaching and Learning. Retrieved from http://www.cimt.plymouth.ac.uk/journal/morgan.pdf on 13.09.2010.

Chang, Y. K., Morales, M. A., \& Than, H. (2010). Collaborative learning in wikis. Education for information 28 , DIO 10.3233/EFI-2010-0910

Choate, M. (2008). Professional wikis. Indianapolis, USA: Wiley Publishing.

Cole, M. (2009). Using Wiki technology to support student engagement: Lessons from the trenches. Computers \& Education, 52(1), 141-146.

Duffy, P., \& Bruns, A. (2006). The use of blogs, wikis and RSS in education: A conversation of possibilities. Proceedings of the Online Learning and Teaching Conference 2006, Brisbane: September 26.31-38.

Fountain, R. (2005). Wiki pedagogy. Dossiers technopédagogiques, 319-325

Franklin, T., \& Van Harmelen, M. (2007). Web 2.0 for content for learning and teaching in higher education. Retrieved from https:/staff.blog.ui.ac.id/harrybs/files/2008/10/web-2-for-content-for-learning-and-teaching-in-highereducation.pdf

Franco, C. D. P. (2008). Using wiki-based peer-correction to develop writing skills of Brazilian EFL learners. NovitasRoyal, 2(1), 49-59.

Gokcearslan, S., \& Ozcan, S. (2011). Place of wikis in learning and teaching process. Procedia-Social and Behavioral Sciences, 28, 481-485.

Grant, L. (2006). Using wikis in schools: A case study. FutureLab. Retrieved from http://www.futurelab.org.uk/resources/publications-reports-articles/disc

Grant, L. (2009). 'I DON'T CARE DO UR OWN PAGE!'A case study of using wikis for collaborative work in a UK secondary school. Learning, Media and Technology, 34(2), 105-117.

Grayson, D.R., Anderson, Terry (2003). E-learning in the 21st century: (theoretical and practical). TranslationIsmailand SaeedZareiZvarkyunitaryfun. Tehran. Science and Technology. First Edition. (1384).

Hampel, T., Selke, H., \& Vitt, S. (2005). "Deployment of simple user-centered collaborative technologies in educational institutions - Experiences and requirements". Proceedings of the 14th IEEE International Workshops on Enabling Technologies, Linköping, Sweden: June 13-15, 207-214

Hester, A. J., \& Scott, J. E. (2008, 7ᄀ10 Jan. 2008). A Conceptual Model of Wiki Technology Diffusion. Paper presented at the Hawaii International Conference on System Sciences, Proceedings of the 41st Annual.

Kane, G. C., \& Fichman, R. G. (2009). The shoemaker's children: using wikis for information systems teaching, research, and publication. MIS quarterly, 33(1), 1-17. 
Lamb, A., \& Johnson, L. (2007). An information skills workout: Wikis and collaborative writing. Teacher-Librarian, $34,57-59$

Lamb, B. (2004). Wide open spaces: Wikis, ready or not. Educause Review, 39(5), 34-69.

Leuf, B., \& Cunningham, W. (2001). The wiki way: Collaboration and sharing on the internet. Boston : AddisonWesley Professional.

Lin, H., \& Kelsey, K. (2010). A case of using wikis to foster collaborative learning: Pedagogical potential and recommendations. In Y. Inoue (Eds.), Cases on online and blended learning techniques in higher education: Concepts and practices (pp. 167-182). Hershey, PA: IGI Global.

Lin, B., \& Hsieh, C. (2010). Web-based teaching and learner control: A research view. Computers and Education, 37 , 377-386.

Mahdavi Nasab, J. (2011). The effect of blogs on collaborative learning, (Unpublished doctoral dissertation). Faculty of Psychology and Sciences of Education, Allameh Tabatabai University, Tehran.

Mirzajani, H., HajiAlizadeh, K., Hashemi Gorji, O., Mohammadi, S. E., Sohaei, R., Delaviz Bayekolae, M. (2015). The Need for Recognition and Implementation of Educational Technologies by Teachers in the Educational and Learning Process. International Journal of Learning and Development, 5(3), 14-23.

Notari, M. (2006) How to use a wiki in education: wiki based effective constructive learning. Proceedings of the 2006 International Symposium on Wikis, Odense, Denmark.

Oblinger, D., Oblinger, J. L., \& Lippincott, J. K. (2005). Educating the net generation. Boulder, Colo.: EDUCAUSE, c2005. 1 v. (various pagings): illustrations.

Pifarré, M., \& Li, L. (2012). Teaching how to learn with a wiki in primary education: What classroom interaction can tell us. Learning, Culture and Social Interaction, 1(2), 102-113.

Parker, K. R., \& Chao, J. T. (2007). Wiki as a teaching tool. Interdisciplinary Journal of Knowledge and Learning Objects, 3, 57-72.

Ramanau, R., \& Geng, F. (2008). Researching the use of Wiki's to facilitate group work. Procedia-Social and Behavioral Sciences, 1(1), 2620-2626.

Shirky, C. (2004). Wikis, graffiti, and process, many-to-many: Social software, Retrieved from http://many.corante.com/.shtml on

Standing, C., \& Kiniti, S. (2011). How can organizations use wikis for innovation? Technovation, (7) 295-287.

Turnbull, G. (2004). Talking to Ward Cunningham about wiki. Retrieved from http://gorjuss.com/luvly/ $\neg$ wardcunningham.html on

Wagner, C., \& Majchrzak, A. (2007). Enabling customer-centricity using wikis and the wiki way. Journal of management information systems, (3), 17-43.

West, J. A., \& West, M. L. (2008). Using wikis for online collaboration: The power of the read-write web (Vol. 15). New York: John Wiley \& Sons. 